\title{
Increase in prevalence of physician-diagnosed asthma in Helsinki during the Finnish Asthma Programme: improved recognition of asthma in primary care? A cross-sectional cohort study
}

\section{*Annette Kainu', Paula Pallasaho², Päivi Piirilä, Ari Lindqvist ${ }^{4}$, Anssi Sovijärvi ${ }^{5}$, Anne Pietinalho ${ }^{6}$}

\footnotetext{
1 Division of Respiratory Medicine, Department of Medicine, Helsinki University Central Hospital, Peijas Hospital, Vantaa, Finland

${ }^{2}$ Control of Hypersensitivity Diseases, Finnish Institute of Occupational Health, Helsinki, Finland

${ }^{3}$ Laboratory of Clinical Physiology, Division of Clinical Physiology and Nuclear Medicine, Laboratory Department, Helsinki University Central Hospital, Helsinki, Finland

${ }^{4}$ Research Unit of Pulmonary Diseases, Division of Pulmonary Medicine, Department of Medicine, Helsinki University Central Hospital, Helsinki, Finland

${ }^{5}$ Division of Clinical Physiology and Nuclear Medicine, Laboratory Department, Helsinki University Central Hospital and University of Helsinki, Helsinki, Finland

${ }^{6}$ Finnish Lung Health Association (Filha), Helsinki, Finland and Raasepori Health Care Center, Tammisaari, Finland
}

Originally received 2nd September 2012; resubmitted 18th November 2012; revised 28th November 2012; accepted 30th November 2012; online 8th January 2013

\begin{abstract}
Background: The continuing rise in asthma prevalence has been questioned, with recent reports suggesting a plateau.

Aims: To assess a 10-year trend in the age-adjusted prevalence of physician-diagnosed asthma, respiratory and allergic symptoms, and use of asthma medication in the adult population of Helsinki during the Finnish Asthma Programme from 1994 to 2004.

Methods: Two cross-sectional postal surveys were conducted among random Finnish National Population Registry samples 10 years apart using the same protocol. A total of 6,062 subjects (75.9\%) and 2,449 subjects (61.9\%) participated in 1996 and 2006 , respectively.

Results: The prevalence of physician-diagnosed asthma increased from $6.5 \%$ in 1996 to $10.0 \%$ in 2006 ( $p<0.001)$. This was evident in both genders aged $<60$ years, but particularly in women aged $<40$ years, paralleling an increased use of asthma medication. Concurrently, the prevalence of allergic rhinoconjunctivitis increased from $37.2 \%$ to $44.4 \%$ ( $p<0.001)$. The prevalence of physician-diagnosed chronic obstructive pulmonary disease remained unchanged (3.7\%), while current smoking abated. Subjects with a smoking history had more respiratory symptoms $(p<0.001)$. Among subjects without physician-diagnosed asthma, those reporting allergic rhinoconjunctivitis had a higher prevalence of lower respiratory tract symptoms.

Conclusions: The prevalence of allergic rhinoconjunctivitis and physician-diagnosed asthma has increased in Helsinki during 10 years in adults, especially in women aged $<40$ years. Concomitantly, the use of asthma medication increased and subjects with physiciandiagnosed asthma were less symptomatic. The increase in the prevalence of physician-diagnosed asthma may partly be due to improved diagnostic recognition of asthma in primary care during the Finnish Asthma Programme, but the concurrent rise in allergic rhinoconjunctivitis may reflect a true rise in prevalence.

(C) 2013 Primary Care Respiratory Society UK. All rights reserved.

A Kainu et al. Prim Care Respir J 2013; 22(1): 64-71

http://dx.doi.org/10.4104/pcrj.2013.00002
\end{abstract}

Keywords asthma, allergic rhinitis, allergy, epidemiology, smoking, COPD

\footnotetext{
* Corresponding author: Dr Annette Kainu, Division of Respiratory Medicine, Department of Medicine, Helsinki University Central Hospital, Peijas Hospital, Vantaa, Finland; P.O. Box 900, FIN-00029 HUS. Tel: +358-40-735 2763 E-mail: annette.kainu@helsinki.fi
} 
See linked editorial by Bjerg on pg 13

\section{Introduction}

A rising trend in the prevalence of asthma was observed between the 1960s and 1990s, mostly in western countries..$^{1-5}$ Most studies have suggested that a plateau was reached in the late 1990s, ${ }^{6-10}$ but some studies have shown a continuing rise. ${ }^{11,12}$ The prevalence of asthma increased more among women than men in the Copenhagen City Heart Study from 1976-8 to 2001-4. ${ }^{12}$ A steep increase in the prevalence of asthma among women was also reported from Norway, with a greater increase in the prevalence of asthma diagnosis than asthma-related symptoms between 1972 and 1998-9. ${ }^{3}$ In a follow-up study of the European Community Respiratory Health Survey (ECRHS), the proportion of asthma medication users increased more than the proportion of asthmarelated symptoms." Additionally, self-reported nasal allergies increased, especially among the youngest." In Finland, national programmes for asthma from 1994 to 2004 and chronic obstructive pulmonary disease (COPD) from 1998 to 2007 have been conducted to reduce the burden of these diseases. ${ }^{14}$ The timing of our study (1996 and 2006) enables us to assess changes in obstructive respiratory diseases during both national respiratory health programmes.

This is a part of the FinEsS (Finland, Estonia, Sweden) study, which has been in progress from 1996. The main aim of this part was to assess changes in the prevalences and determinants of asthma, allergic rhinoconjunctivitis, and other respiratory symptoms as well as COPD and smoking, comparing population cohorts from 1996 and 2006 using identical questionnaire methods.

\section{Methods}

\section{Population}

The FinEsS study is a joint Nordic project between Finland, Estonia and Sweden on respiratory epidemiology. In Helsinki, similar postal surveys were conducted in 1996 and 2006 to collect information on diagnosed obstructive airways diseases, respiratory symptoms, and precipitating factors among two random population samples aged 20-69 years. Both population samples were obtained from the Finnish National Population Registry on gender and 10-year age cohorts to represent the adult population of Helsinki, Finland. In 1996 a random sample of 8,000 subjects was selected but, of these, 10 individuals had either died or moved outside Helsinki before the questionnaire was mailed and were thus not invited to participate. In order to have a comparable sample, an identical process was applied to the 2006 sample of 4,000 subjects, yielding a random sample of 3,968 individuals. A total of 6,062 subjects (3,462 women) responded in 1996 and 2,449 subjects (1,365 women) responded in 2006, yielding a participation rate of $75.9 \%$ and $61.7 \%$ for 1996 and 2006, respectively. The response rate fell more in the younger groups than in older age cohorts, with the greatest reduction in young women aged $<30$ years from $82.4 \%$ in 1996 to $56.0 \%$ in 2006 (Table 1). The original results from the 1996 survey have been reported elsewhere. ${ }^{15,16}$ The Finnish version of the FinEsS postal survey has been published previously. ${ }^{15}$ The study protocol was approved by the Ethics Committee of the Department of Medicine of Helsinki University Central Hospital.

The characteristics of the two study samples are shown in Table 1. The responders in 2006 were slightly older than in 1996. Current smoking decreased in all age groups except in older men where the prevalence of current smoking remained essentially unchanged (Figure 1).

\section{Definitions}

The definitions of key variables based on the questionnaire answers used are summarised in Table 2. Current smoking is defined as those currently smoking or having smoked cigarettes, pipe, or cigars within one year. Former smokers are those who have quit smoking at least one year previously. Ever smokers include both former and current smokers. Smoking data were not available for $0.2 \%$ of responders in 1996 and $2.0 \%$ of responders in 2006. Obesity was defined as body mass index $(\mathrm{BMl})>30 \mathrm{~kg} / \mathrm{m}^{2}$.

\section{Statistical analysis}

All statistical analyses were conducted with the Statistical Package for Social Sciences (PASW Statistics 20.0; IBM-SPSS Inc, Chicago, IL, USA). The crude prevalence of self-reported diagnoses of obstructive airways diseases and allergies, symptoms, and precipitating factors was calculated first unadjusted for each gender and age cohort, comparing 1996 and 2006 directly. Prevalence figures were ageadjusted to the gender and age distribution of Helsinki in 1996 using National Population Registry sentinel data

Table 1. Characteristics of the studied population samples

\begin{tabular}{|c|c|c|c|c|}
\hline & $\begin{array}{l}1996 \\
\text { Men }\end{array}$ & Women & $\begin{array}{l}2006 \\
\text { Men }\end{array}$ & Women \\
\hline $\mathrm{n}(\%)$ & $2600(42.9 \%)$ & $3462(57.1 \%)$ & $1084(44.3 \%)$ & $1365(55.7 \%)$ \\
\hline Mean (SD) age, years & $42.8(13.1)$ & $42.1(13.3)$ & $45.1(13.9)$ & $45.4(14.3)$ \\
\hline Current smokers, \% & $39.0 \%$ & $30.7 \%$ & $32.9 \%$ & $24.2 \%$ \\
\hline Former smokers, \% & $21.9 \%$ & $14.6 \%$ & $24.4 \%$ & $20.8 \%$ \\
\hline Non-smokers, \% & $39.0 \%$ & $54.8 \%$ & $42.7 \%$ & 55.0 \\
\hline \multicolumn{5}{|l|}{ Response rate } \\
\hline 20-29 years & $61.6 \%$ & $82.4 \%$ & $43.4 \%$ & $56.0 \%$ \\
\hline 30-39 years & $66.0 \%$ & $80.7 \%$ & $51.9 \%$ & $62.7 \%$ \\
\hline $40-49$ years & $68.7 \%$ & $80.3 \%$ & $59.0 \%$ & $66.9 \%$ \\
\hline $50-59$ years & $75.1 \%$ & $83.9 \%$ & $63.8 \%$ & $68.9 \%$ \\
\hline $60-69$ years & $82.3 \%$ & $84.3 \%$ & $73.0 \%$ & $75.9 \%$ \\
\hline
\end{tabular}




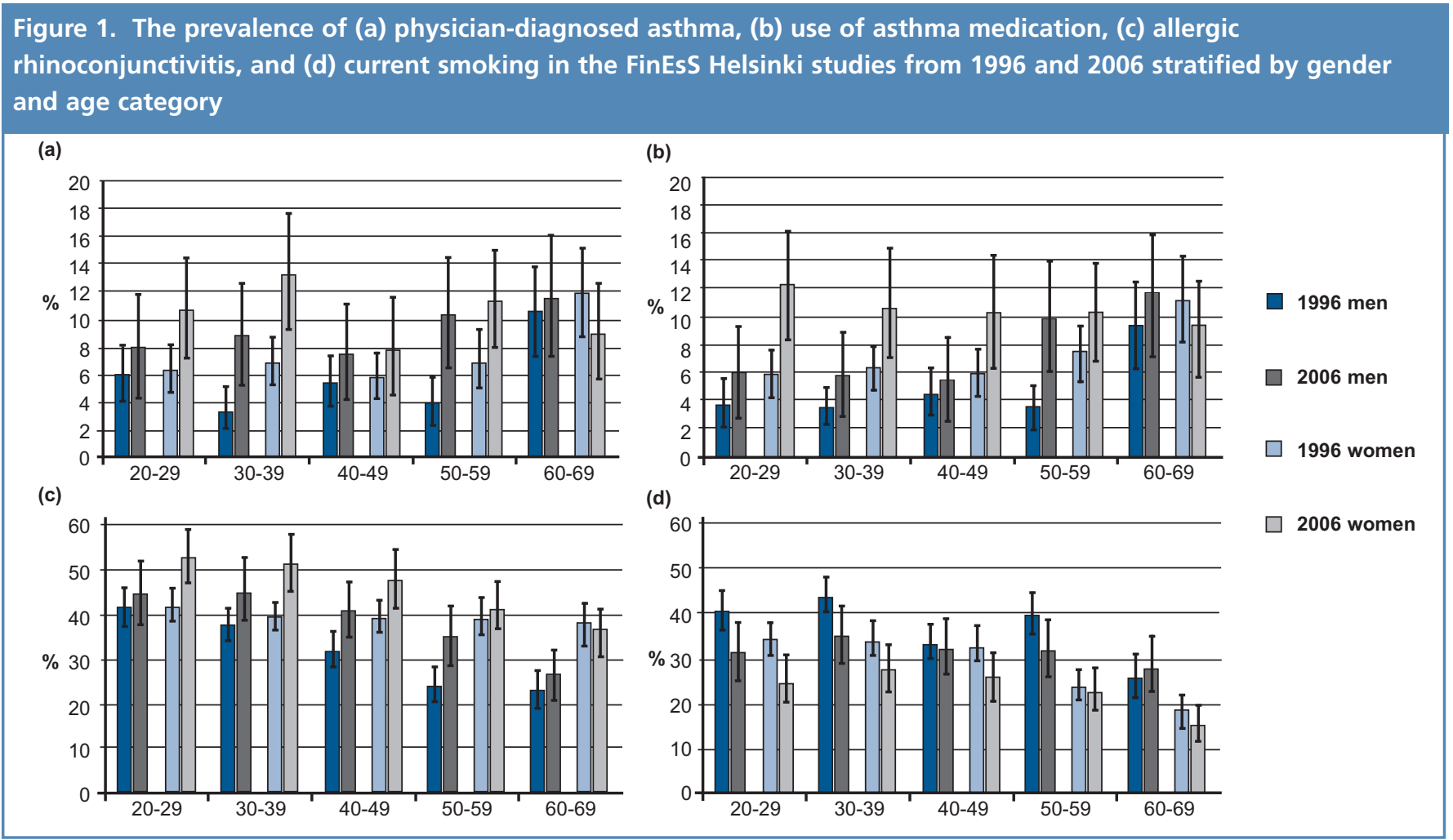

Table 2. Definitions for key variables

\begin{tabular}{ll} 
Variable & Definition: Positive answer to the question \\
\hline Physician-diagnosed asthma & "Have you been diagnosed as having asthma by a doctor?" \\
\hline Physician-diagnosed COPD & "Have you been diagnosed as having chronic bronchitis, COPD or emphysema by a doctor?" \\
\hline Allergic rhinoconjunctivitis & "Do you have now or have you had allergic rhinitis (e.g. hay fever) or allergic eye symptoms?" \\
\hline Past year shortness of breath & "Have you had asthma symptoms (intermittent breathlessness or attacks of breathlessness) during \\
& the previous 12 months?" \\
\hline Longstanding cough & "Have you had longstanding cough during recent years?" \\
\hline Asthma medication & "Do you currently use asthma medication?" \\
\hline Chronic productive cough & $\begin{array}{l}\text { A combined affirmative answer to the questions: "Do you usually have phlegm when coughing, or } \\
\text { do you have phlegm which is difficult to bring up?" and "Do you bring up phlegm on most days } \\
\text { during periods of at least successive three months?" and "Have you had such periods during at least } \\
\text { two successive years?" }\end{array}$ \\
\hline Recurrent wheeze & "Have you had wheezing, whistling, or a noisy sound in your chest when breathing?" \\
\hline Past year wheeze & "Have you had wheezing or whistling in the chest at any time in the last 12 months?" \\
\hline Triad of wheeze & $\begin{array}{l}\text { Combines past year wheeze with two further questions: "Have you been at all breathless when the } \\
\text { wheezing sound was present?" and "Did you have wheezing or whistling when you didn't have a cold?" }\end{array}$ \\
\hline Childhood farm living & Refers to those who report living on a farm during the first 5 years of life
\end{tabular}

(www.vaestorekisterikeskus.fi). Chi-square and Fisher's exact tests were used to analyse differences between groups. A multiple logistic regression model was used to assess the odds ratios for reported diagnoses and symptoms suggestive of asthma between 1996 and 2006, the risk factors for prevalent physician-diagnosed asthma, and self-reported allergic rhinoconjunctivitis; $p$ values $<0.05$ were considered significant in all analyses.

\section{Results}

The age-adjusted prevalence of physician-diagnosed asthma increased from $6.5 \%$ to $10.0 \%(p<0.001)$, with an increase in all age groups except women aged $>60$ years (Figure 1a). Asthma medication was used by $5.9 \%$ in 1996 and by $9.2 \%$ in 2006 $(p<0.001)$, with the steepest increase in young women (20-29 years) from $5.9 \%$ to $12.3 \%(p=0.001)$. Allergic rhinoconjunctivitis was reported by $37.2 \%$ in 1996 and by $44.4 \%$ in 2006 ( $p<0.001$ ), and by $42.0 \%$ and $53.1 \%$ respectively among women aged $<30$ years $(p=0.002$; Figure $1 c)$.

The prevalence of asthma-related symptoms is shown in Table 3. 
Table 3. Age-adjusted* prevalence (\%) of respiratory symptoms by self-reported physician-diagnosed asthma among responders of the FinEsS studies 1996 and 2006

\begin{tabular}{|c|c|c|c|c|c|c|}
\hline & \multicolumn{3}{|c|}{ Physician-diagnosed asthma - } & \multicolumn{3}{|c|}{ Physician-diagnosed asthma + } \\
\hline & $\begin{array}{l}1996 \\
(n=5,664)\end{array}$ & $\begin{array}{l}2006 \\
(n=3,753)\end{array}$ & $\mathrm{p}$ Value & $\begin{array}{l}1996 \\
(n=398)\end{array}$ & $\begin{array}{l}2006 \\
(n=246)\end{array}$ & p Value \\
\hline Past year shortness of breath & $8.5 \%$ & $9.5 \%$ & NS & $75.5 \%$ & $68.4 \%$ & NS \\
\hline Longstanding cough & $18.2 \%$ & $17.2 \%$ & NS & $40.9 \%$ & $32.6 \%$ & 0.044 \\
\hline Chronic productive cough & $10.6 \%$ & $9.1 \%$ & NS & $30.3 \%$ & $23.4 \%$ & NS \\
\hline Recurrent wheeze & $5.0 \%$ & $4.7 \%$ & NS & $37.6 \%$ & $24.9 \%$ & 0.002 \\
\hline Past year wheeze & $16.5 \%$ & $17.9 \%$ & NS & $72.3 \%$ & $63.0 \%$ & 0.017 \\
\hline Triad of wheeze & $4.3 \%$ & $4.8 \%$ & NS & $50.3 \%$ & $36.1 \%$ & $<0.001$ \\
\hline \multicolumn{7}{|c|}{ Dyspnoea, wheezing or severe cough induced by } \\
\hline Exercise in cold & $19.8 \%$ & $20.1 \%$ & NS & $76.4 \%$ & $74.4 \%$ & NS \\
\hline Animal or pollen & $16.4 \%$ & $18.4 \%$ & NS & $70.4 \%$ & $65.6 \%$ & NS \\
\hline Allergic rhinoconjunctivitis & $34.7 \%$ & $40.5 \%$ & $<0.001$ & $74.4 \%$ & $78.7 \%$ & NS \\
\hline Asthma medication & $1.4 \%$ & $2.6 \%$ & $<0.001$ & $70.0 \%$ & $68.8 \%$ & NS \\
\hline Physician-diagnosed COPD & $2.7 \%$ & $1.8 \%$ & NS & $14.4 \%$ & $14.0 \%$ & NS \\
\hline
\end{tabular}

Table 4. Age-adjusted* prevalence of respiratory symptoms by smoking status among responders of the FinEsSHelsinki 1996 and 2006 studies

\begin{tabular}{|c|c|c|c|c|c|c|c|c|}
\hline & \multicolumn{4}{|l|}{1996} & \multicolumn{4}{|l|}{2006} \\
\hline & $\begin{array}{l}\text { Non- } \\
\text { smokers } \\
(n=2,937)\end{array}$ & $\begin{array}{l}\text { Former } \\
\text { smokers } \\
(n=1,007)\end{array}$ & $\begin{array}{l}\text { Current } \\
\text { smokers } \\
(n=2,118)\end{array}$ & $\mathrm{p}$ Valuet & $\begin{array}{l}\text { Non- } \\
\text { smokers } \\
(n=1,203)\end{array}$ & $\begin{array}{l}\text { Former } \\
\text { smokers } \\
(n=526)\end{array}$ & $\begin{array}{l}\text { Current } \\
\text { smokers } \\
(n=720)\end{array}$ & $\mathrm{p}$ Valuet \\
\hline Past year shortness of breath & $10.4 \%$ & $15.0 \%$ & $15.4 \%$ & $<0.001$ & $11.7 \%$ & $16.0 \%$ & $21.0 \%$ & $<0.001$ \\
\hline Longstanding cough & $16.4 \%$ & $18.2 \%$ & $25.2 \%$ & $<0.001$ & $16.1 \%$ & $14.9 \%$ & $25.5 \%$ & $<0.001$ \\
\hline Recurrent wheeze & $3.8 \%$ & $6.2 \%$ & $12.4 \%$ & $<0.001$ & $3.0 \%$ & $4.8 \%$ & $14.2 \%$ & $<0.001$ \\
\hline Past year wheeze & $13.0 \%$ & $19.2 \%$ & $30.7 \%$ & $<0.001$ & $13.8 \%$ & $19.6 \%$ & $38.7 \%$ & $<0.001$ \\
\hline Triad of wheeze & $4.8 \%$ & $8.0 \%$ & $10.5 \%$ & $<0.001$ & $5.5 \%$ & $8.4 \%$ & $11.6 \%$ & $<0.001$ \\
\hline Cold and exercise-provoking symptoms & $20.5 \%$ & $23.3 \%$ & $28.3 \%$ & $<0.001$ & $22.1 \%$ & $22.8 \%$ & $33.0 \%$ & $<0.001$ \\
\hline Pollen-provoking symptoms & $15.7 \%$ & $17.9 \%$ & $17.2 \%$ & NS & $18.1 \%$ & $20.6 \%$ & $22.5 \%$ & 0.043 \\
\hline
\end{tabular}

Shortness of breath during the past year was overall reported more frequently in 2006, with an increase from $12.9 \%$ to $15.4 \%$ $(p=0.006)$. Subjects reporting physician-diagnosed asthma had slightly fewer symptoms, although this difference was not statistically significant.

Of those subjects reporting shortness of breath during the past year, physician-diagnosed asthma was reported by $37.6 \%$ and $44.6 \%$ in 1996 and 2006, respectively. Likewise, of those subjects reporting wheeze during 12 months and the triad of wheeze (for definitions see Table 2), $23.2 \%$ and $28.1 \%$ in 1996 and $44.1 \%$ and $46.2 \%$ in 2006 reported having physician-diagnosed asthma. Longstanding cough was reported by $19.8 \%$ in 1996 and by $18.7 \%$ in 2006 and chronic productive cough by $11.9 \%$ and $10.5 \%$, respectively, with no significant change. The prevalence of current smoking decreased in all age groups except in men aged $>60$ years
(Figure 1d). The prevalence of physician-diagnosed COPD remained at $3.7 \%$ overall (age-adjusted prevalence $3.0 \%$ ), with $17.1 \%$ of subjects with asthma also reporting a diagnosis of COPD.

All respiratory symptoms except allergen-induced symptoms were significantly associated with smoking habits (Table 4). In 2006 the prevalence of recurrent wheeze increased from 3.0\% in nonsmokers to $14.2 \%$ in current smokers and wheeze in the past year from $13.8 \%$ to $38.7 \%$ correspondingly. The prevalence of positive answers to the triad of past year wheeze, wheeze with dyspnoea and wheeze outside colds was $5.5 \%$ in non-smokers, $8.4 \%$ in former smokers, and $11.6 \%$ in current smokers ( $p<0.001)$.

In the 2006 cohort, allergic rhinoconjunctivitis was associated with a higher age-adjusted prevalence of all respiratory symptoms in subjects without asthma: the triad of wheeze increased from $2.5 \%$ to $8.0 \%$ and past year shortness of breath from $4.5 \%$ to $16.5 \%$ in 


\begin{tabular}{|c|c|c|c|c|c|c|c|c|}
\hline & \multicolumn{4}{|l|}{1996} & \multicolumn{4}{|l|}{2006} \\
\hline & \multicolumn{2}{|c|}{$\begin{array}{l}\text { Physician-dg } \\
\text { asthma - }\end{array}$} & \multicolumn{2}{|c|}{$\begin{array}{l}\text { Physician-dg } \\
\text { asthma + }\end{array}$} & \multicolumn{2}{|c|}{$\begin{array}{l}\text { Physician-dg } \\
\text { asthma - }\end{array}$} & \multicolumn{2}{|c|}{$\begin{array}{l}\text { Physician-dg } \\
\text { asthma + }\end{array}$} \\
\hline & $\begin{array}{l}\text { ARC - } \\
n=3,714 \\
(65.6 \%)\end{array}$ & $\begin{array}{l}\text { ARC + } \\
n=1,950 \\
(34.4 \%)\end{array}$ & $\begin{array}{l}\text { ARC - } \\
n=112 \\
(28.1 \%)\end{array}$ & $\begin{array}{l}A R C+ \\
n=286 \\
(71.9 \%)\end{array}$ & $\begin{array}{c}\text { ARC - } \\
n=1,343 \\
(61.0 \%)\end{array}$ & $\begin{array}{l}A R C+ \\
n=860 \\
(39.0 \%)\end{array}$ & $\begin{array}{l}\text { ARC - } \\
n=59 \\
(24.0 \%)\end{array}$ & $\begin{array}{l}\mathrm{ARC}+ \\
\mathrm{n}=187 \\
(76.0 \%)\end{array}$ \\
\hline Past year shortness of breath & $4.1 \%$ & $17.0 \%$ & $72.3 \%$ & $76.9 \%$ & $4.5 \%$ & $16.4 \%$ & $69.5 \%$ & $69.0 \%$ \\
\hline Longstanding cough & $13.9 \%$ & $26.6 \%$ & $46.4 \%$ & $41.6 \%$ & $13.1 \%$ & $23.5 \%$ & $32.2 \%$ & $35.8 \%$ \\
\hline Chronic productive cough & $8.1 \%$ & $15.8 \%$ & $32.1 \%$ & $31.1 \%$ & $7.6 \%$ & $12.4 \%$ & $27.1 \%$ & $25.1 \%$ \\
\hline Recurrent wheeze & $3.5 \%$ & $8.1 \%$ & $36.6 \%$ & $39.2 \%$ & $3.9 \%$ & $7.0 \%$ & $32.2 \%$ & $24.6 \%$ \\
\hline Past year wheeze & $12.2 \%$ & $24.3 \%$ & $64.3 \%$ & $74.5 \%$ & $12.8 \%$ & $25.2 \%$ & $62.7 \%$ & $62.6 \%$ \\
\hline Triad of wheeze & $2.3 \%$ & $8.2 \%$ & $40.2 \%$ & $53.5 \%$ & $2.6 \%$ & $7.9 \%$ & $30.5 \%$ & $36.4 \%$ \\
\hline Exercise in cold-provoking symptoms & $15.4 \%$ & $27.7 \%$ & $74.1 \%$ & $78.7 \%$ & $15.3 \%$ & $27.3 \%$ & $62.7 \%$ & $76.5 \%$ \\
\hline Pollen-provoking symptoms & $2.2 \%$ & $35.8 \%$ & $24.1 \%$ & $67.1 \%$ & $3.1 \%$ & $40.5 \%$ & $28.8 \%$ & $75.9 \%$ \\
\hline
\end{tabular}

Figure 2. Adjusted odds ratios (OR) for physician-diagnosed obstructive airways diseases, use of asthma medication, allergic rhinoconjunctivitis, and symptoms suggestive of obstructive airways diseases assessed with a multiple logistic regression model adjusting for categorised age decade, gender, and smoking history between 2006 and 1996

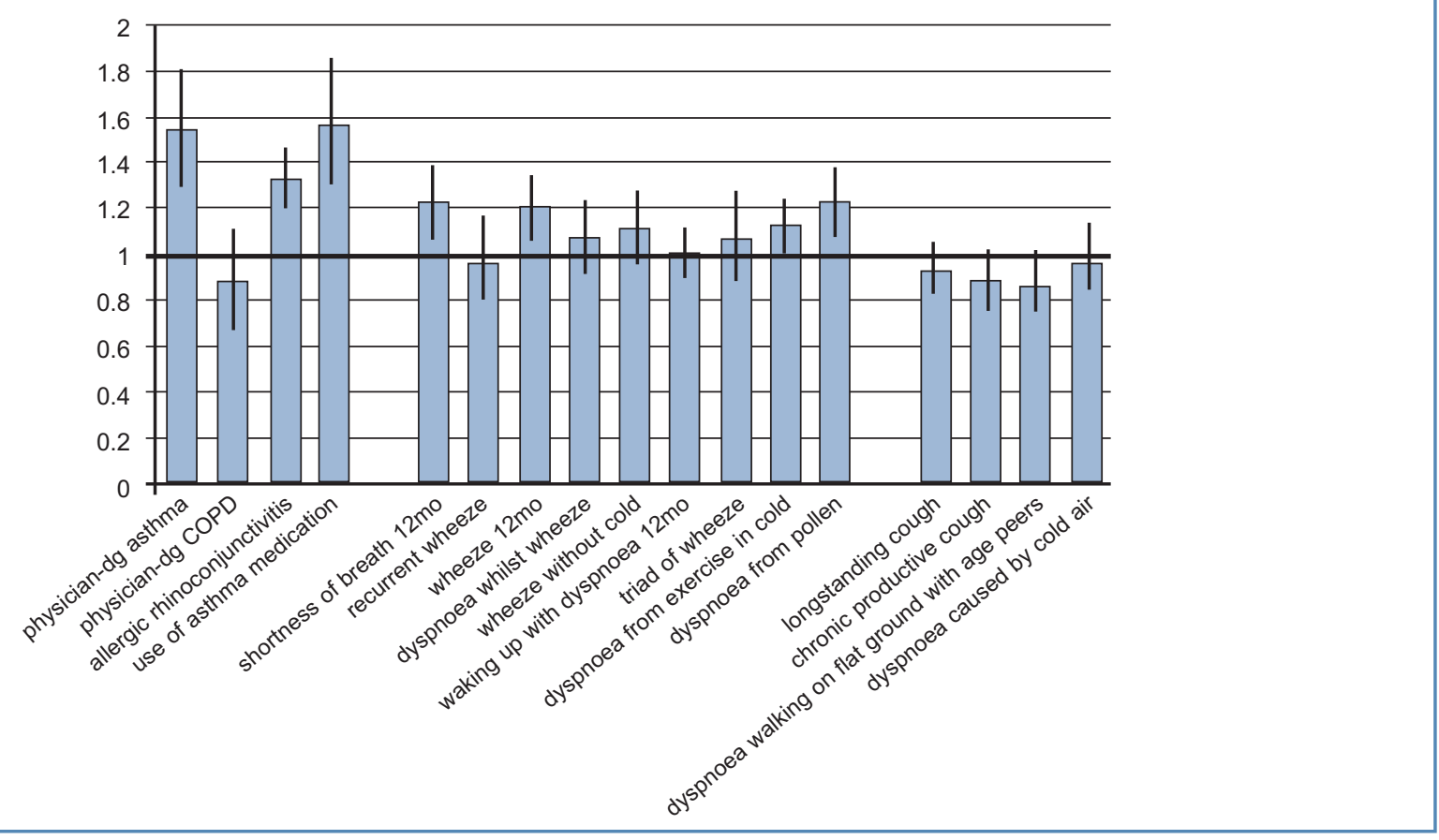

subjects who reported not having or having allergic rhinoconjunctivitis, respectively (Table 5). In subjects with both asthma and allergic rhinoconjunctivitis, respiratory symptoms provoked by allergens and exercise in cold were more common than among those without rhinitis, but no significant difference between the groups was found for other respiratory symptoms. Although the prevalence of physician-diagnosed asthma increased, the prevalence of respiratory symptoms among patients with asthma decreased (Table 3).
In a multivariate logistic regression model in the 2006 cohort, the risk of physician-diagnosed asthma was significantly increased by allergic rhinoconjunctivitis (odds ratio (OR) $4.32,95 \% \mathrm{Cl} 3.13$ to 5.98; $p<0.001$ ), family history of asthma (OR $1.83,95 \% \mathrm{Cl} 1.34$ to 2.48; $\mathrm{p}<0.001$ ), and obesity defined as $\mathrm{BMI}>30 \mathrm{~kg} / \mathrm{m}^{2}$ (OR 1.63 , $95 \% \mathrm{Cl} 1.13$ to $2.34 ; \mathrm{p}=0.009$ ) after adjusting for gender, family history of allergic rhinoconjunctivitis, age $<40$ years, ever smoking, workplace exposure to vapours, gases, dusts or fumes (VGDF), and living on a farm as a child. In a comparable model, the risk of allergic 
rhinoconjunctivitis was significantly increased by a family history of allergic rhinoconjunctivitis (OR 4.65, 95\% Cl 3.85 to 5.61; $p<0.001$ ) and workplace exposure to VGDF (OR $1.43,95 \% \mathrm{Cl} 1.17$ to 1.74 ; $\mathrm{p}<0.001)$. Living on a farm during the first five years of life was inversely associated with allergic rhinoconjunctivitis (OR 0.73, 95\% Cl 0.57 to $0.93 ; p=0.01$ ).

The trends for physician-diagnosed obstructive airways diseases, use of asthma medication, allergic rhinoconjunctivitis, and symptoms suggestive of obstructive airways diseases were assessed with a multiple logistic regression model adjusting for categorised age decade, gender and smoking history between 2006 and 1996 (Figure 2). Odds ratios were $1.53(95 \% \mathrm{Cl} 1.29$ to 1.81$)$ for physician-diagnosed asthma, $1.56(95 \% \mathrm{Cl} 1.31$ to 1.85$)$ for use of asthma medication, and $1.33(95 \% \mathrm{Cl} 1.21$ to 1.47$)$ for allergic rhinoconjunctivitis.

\section{Discussion}

\section{Main findings}

The present study shows an increase in the prevalence of physiciandiagnosed asthma and self-reported allergic rhinoconjunctivitis in subjects aged <60 years during 10 years from 1996 to 2006 in Helsinki. The steepest increase was found among women aged $<40$ years. This increased prevalence of physician-diagnosed asthma during the Finnish Asthma Programme (from 1994 to 2004) was paralleled by an increase in the use of asthma medication, which doubled among young women.

\section{Strengths and limitations of this study}

The FinEsS Helsinki Study has been conducted from 1996 using identical methods in sampling a non-selected population sample from the National Population Registry and identical postal questionnaire items. In 1996 a non-responder study was conducted in the concurrent FinEsS Kemi Study, which showed that typical nonresponders were young men and current smokers who reported respiratory symptoms in exercise and asthma less frequently than the responders in the original study. ${ }^{17}$ There was a decline in the response rate from 1996 to 2006, but similar response rates during the last years have been reported from other national questionnaire studies. ${ }^{10,12}$ The response rate fell more in younger age cohorts than in older age cohorts, with youngest women having the largest reduction. This can affect the results since we cannot exclude the possibility that people with asthma were more likely to respond, which can increase the prevalence in these age groups. The total number of answers in the actual study was satisfactory.

\section{Interpretation of findings in relation to previously} published work

The simultaneous increase in the prevalence of allergic rhinoconjunctivitis and physician-diagnosed asthma suggests that the impact of allergies continues to rise in the population. The changes in prevalence of past year shortness of breath and asthma were in parallel. A recent report showed similar results from the Finnish Karelia, where allergic rhinoconjunctivitis and asthma were significantly more common in 2007 than in $1997 .{ }^{18}$ It is possible that the increase in the prevalence of physician-diagnosed asthma could in part be due to increased awareness by patients and general practitioners following the Finnish Asthma Programme. Also, improved diagnostic processes - including the use of objective measurements of airway obstruction with spirometry and approved criteria of tests for bronchial hyperresponsiveness in Finland - could explain this rise to some extent. ${ }^{13,19,20}$ Thus, the milder forms of the disease might have been better recognised and diagnosed as asthma already in primary care. Those reporting physician-diagnosed asthma were less symptomatic in 2006 than in 1996, which may be related to more active treatment of asthma promoted by the Asthma Programme in Finland. ${ }^{13}$ On the other hand, no change in respiratory symptoms was found among those without asthma.

There are differing views on the best method of defining asthma prevalence in epidemiological studies of trends. In a recent publication from Sweden, an increase in 'current asthma' from 6.3\% to $7.8 \%$ between 1990 and 2008 was reported and the proportion of subjects using asthma medication increased from $5.2 \%$ to $6.9 \%{ }^{21}$ These results are in line with our findings. However, the authors consider that a reduction in symptoms would be a more reliable measure of asthma prevalence and conclude that the rise in asthma prevalence has reached a plateau in Sweden. In countries with highly developed primary care services, with established national guidelines and reimbursement policies that are based on clinical physiological verification of disease, physician diagnoses of established disease are, in our view, a more reliable measure of the trend in disease prevalence. However, we also agree that diagnostic labelling is affected by healthcare policies.

The National Registry for Social Security benefits was searched for data on the number of patients entitled to special reimbursement for asthma medication in Finland (www.kela.fi). An increase from 99,665 cases in 1996 to 135,661 cases in 2006 was found among those aged 20-69 years, which is consistent with our results.

An increasing prevalence of asthma has been found in many parts of the world..$^{22}$ In our study, the increase in prevalence was greatest among women aged $<40$ years, which is consistent with results from Denmark and Norway., ${ }^{3,12}$ What is the explanation for this increase in allergy symptoms and asthma among younger age groups? Environmental factors including living on a farm at early ages seems to be protective for allergic rhinoconjunctivitis, which could partially explain the increased prevalence of asthma in younger adults who are less likely to have lived in the countryside during childhood. In the study by Browatzki et al. it was hypothesised that the increase is associated with obesity. ${ }^{12}$ Unfortunately, we have no data on weight from 1996 and thus are not able to assess the impact of obesity on the trend between 1996 and 2006; but in 2006 our study confirms this finding with $\mathrm{BMI}>30 \mathrm{~kg} / \mathrm{m}^{2}$ being a significant risk factor for physician-diagnosed asthma. Similarly, recent data from Finnish Karelia found that younger generations were more atopic than older ones. ${ }^{18}$ Our results are also in line with those from Denmark and Norway showing the steepest increase among young women, which suggests that changes in the immunological tolerance have been stronger in women than in men for some unexplained reason.

Allergic rhinoconjunctivitis was common in all age groups, reflecting present or past self-assessed allergic eye or nose 
symptoms. We found a protective effect of living on a farm during the first five years of life for allergic rhinoconjunctivitis in adulthood. This protective effect was of similar magnitude to that recently found in Sweden. ${ }^{23}$ This suggests that immunological changes occurring in early childhood in a farm environment persist in adulthood. An increased risk of allergic rhinoconjunctivitis was also associated with occupational exposure to vapours, gases, dusts or fumes (VGDF). This effect was stronger in our cohort than in the Swedish study. ${ }^{23}$

The continuing educational work in smoking cessation and changes in the legislation have resulted in a decreased prevalence of current smokers in all but the oldest age groups. Despite this decrease, the prevalence of asthma continued to increase, which is in line with results from the Copenhagen City Heart Study. ${ }^{12}$ Decreased smoking habits may have contributed to the better control of asthma seen in 2006 as well as the plateau in respiratory symptoms among non-asthmatics, since all symptoms were found to be strongly associated with smoking. The remaining prevalence of typical asthma symptoms such as shortness of breath during the past year $(9.5 \%)$ suggests that there might still remain a degree of underdiagnosis of obstructive airways diseases in this population. The increase in asthma diagnoses in younger adults might reflect the fact that asthma is more often considered when respiratory symptoms are investigated in younger adults.

In both the 1996 and 2006 studies the prevalence of physiciandiagnosed COPD remained at the same level despite the implementation of the Finnish COPD Programme and better awareness of COPD among physicians in primary care. ${ }^{24,25}$ The decreasing smoking habits have probably contributed to the fact that chronic productive cough remained at the same level and no increase in physician-diagnosed COPD was found. The WHO Global Burden of Disease Study has predicted COPD to rise to be the fifth leading cause of loss of disability-adjusted life years in the world by $2020 .{ }^{26}$ Prevalence estimates of COPD have varied from $4 \%$ to $10 \%$ internationally. ${ }^{27,28}$ In the Obstructive Lung Disease in Northern Sweden (OLIN) study, the prevalence of COPD was $8-14 \%$ among those aged $>45$ years depending on the lung function criteria used for the diagnosis. ${ }^{29}$ Similarly, the prevalence of COPD in Finland varied from $5 \%$ to $9 \%$ depending on the criteria used..$^{30}$ In a recent Finnish study, no significant change in the prevalence of COPD was found between 1978-80 and 2000-1. ${ }^{31}$

Implications for future research, policy and practice Our results indicate that perhaps milder forms of asthma were recognised particularly in younger adults among whom allergic rhinoconjunctivitis is also more prevalent. Patients with diagnosed asthma were less symptomatic, which could be attributed to more active pharmacological treatment, also seen as an increase in the National Medical Reimbursement Statistics for asthma medication. The diagnostic labelling of COPD is clearly more limited, but the changes in reimbursement criteria for COPD were only implemented in 2006 so are yet to be reflected in this study. A follow-up study on the prevalence of asthma, allergic rhinoconjunctivitis, and COPD is planned for 2013 and 2016 to further evaluate the impacts of the Finnish Asthma Programme, Finnish COPD Programme, and the ongoing Finnish Allergy Programme. A more in-depth understanding of the diagnostic labelling and patient management practices in primary care and their implications for healthcare costs and diagnostic accuracy are clearly needed.

\section{Conclusions}

The results indicate that no plateau in the increase of asthma has yet been attained in Finland in terms of physician-diagnosed asthma, but the patients diagnosed with asthma are less symptomatic and receive more active treatment. The increase in asthma prevalence might be partly due to improved diagnostic processes and recognition of asthma in primary care in Finland following the Finnish Asthma Programme. Allergic rhinoconjunctivitis increased the respiratory symptoms in subjects without physician-diagnosed asthma, suggesting a remaining group of patients with undiagnosed asthma and a true rise in the prevalence of asthma. Further studies are needed to evaluate whether earlier diagnosis and active treatment of milder cases will eventually contribute to more patients with asthma reaching remission.

\section{Handling editor Arnulf Langhammer Statistical review Gopal Netuveli}

Acknowledgements The authors thank the personnel who undertook the questionnaire study at the Finnish Lung Health Association (Filha) and Associate Professor Janne Pitkäniemi, University of Helsinki, for his advice on statistical analyses.

Conflicts of interest The authors declare that they have no conflicts of interest in relation to this article.

Contributorship AK conducted the data processing and analysis and produced the tables and figures for the article. AK and PP drafted the text of the article. AP organised the questionnaire study of 2006 in the Finnish Lung Health Association and participated in editing the paper. PP participated in planning of the original study. AL and AS participated in editing the paper and coordinating the FinEsS Helsinki study.

Funding The FinEsS-project was funded by the Helsinki University Central Hospital special governmental subsidy for health sciences research project code TYH1235. In 2006 the cost of the questionnaire study was covered by the Finnish Lung Health Association (Filha). AK has received funding with a personal research leave from the Helsinki University Central Hospital special governmental subsidy for health sciences research (2009), the Finnish Anti-Tuberculosis Foundation (2008) and the Research Foundation for Respiratory Research (2008).

\section{References}

1. Hansen EF, Rappeport Y, Vestbo J, Lange P. Increase in prevalence and severity of asthma in young adults in Copenhagen. Thorax 2000;55:833-6. http://dx.doi.org/10.1136/thorax.55.10.833

2. Pallasaho $P$, Lundbäck $B$, Meren $M$, et al. Prevalence and risk factors for asthma and chronic bronchitis in the capitals Helsinki, Stockholm, and Tallinn. Respir Med 2002;96:759-69. http://dx.doi.org/10.1053/rmed.2002.1308

3. Brogger J, Bakke P, Eide GE, Johansen B, Andersen A, Gulsvik A. Long-term changes in adult asthma prevalence. Eur Respir J 2003;21:468-72. http://dx.doi.org/ 10.1183/09031936.03.00056103

4. Eder W, Ege MJ, von Mutius E. The asthma epidemic. N Eng/ J Med 2006;355:222635. http://dx.doi.org/10.1056/NEJMra054308

5. Martinez FD. Trends in asthma prevalence, admission rates, and asthma deaths. Respir Care 2008;53:561-7.

6. Braun-Fahrländer $\mathrm{CH}$, Gassner M. No further increase in asthma, hay fever and atopic sensitization in adolescents living in Switzerland. Eur Respir J 2004;23:407-13. http://dx.doi.org/10.1183/09031936.04.00074004

7. Nowak D, Ulrik CS, von Mutius E. Asthma and atopy: has peak prevalence been reached? Eur Respir J 2004;23:359-60. http://dx.doi.org/10.1183/ 09031936.04.00134004 
8. von Hertzen L, Haahtela T. Signs of reversing trends in prevalence of asthma. Allergy 2005;60:283-92. http://dx.doi.org/10.1111/j.1398-9995.2005.00769.x

9. Anderson HR, Gupta R, Strachan DP, Limb ES. 50 years of asthma: UK trends from 1955 to 2004. Thorax 2007;62:85-90. http://dx.doi.org/10.1136/thx.2006.066407

10. Lötvall J, Ekerljung L, Rönmark EP, et al. West Sweden Asthma Study: prevalence trends over the last 18 years argues no recent increase in asthma. Respir Res 200910:94, E-pub.

11. Chinn $S$, Jarvis $D$, Burney $B$, et al. Increase in diagnosed asthma but not in symptoms in the European Community Respiratory Health Survey. Thorax 2004;59:646-51. http://dx.doi.org/10.1136/thx.2004.021642

12. Browatzki A, Suppli C, Ulrik MD, Lange P. Prevalence and severity of self-reported asthma in young adults, 1976-2004. Eur Respir J 2009;34:1046-51. http://dx.doi.org/10.1183/09031936.00177908

13. Haahtela T, Tuomisto LE, Pietinalho A, et al. A 10 year asthma programme in Finland: major change for the better. Thorax 2006;61:663-70. http://dx.doi.org/ 10.1136/thx.2005.055699

14. Laitinen LA, Koskela K. Chronic bronchitis and chronic obstructive pulmonary disease: Finnish National Guidelines for Prevention and Treatment 1998-2007. Respir Med 1999;93:297-332. http://dx.doi.org/10.1016/S0954-6111(99)90313-X

15. Pallasaho $P$, Lundbäck $B$, Läspä $S L$, et al. Increasing prevalence of asthma but not of chronic bronchitis in Finland? Report from the FinEsS-Helsinki study. Respir Med 1999;93:798-809. http://dx.doi.org/10.1016/S0954-6111(99)90265-2

16. Pallasaho P, Meren M, Raukas-Kivioja A, Rönmark E. Different labeling of obstructive airway diseases in Estonia, Finland, and Sweden. Eur J Epidemiol 2005;20:975-83. http://dx.doi.org/10.1007/s10654-005-4117-6

17. Kotaniemi J-T, Hassi J, Kataja M, et al. Does non-responder bias have a significant effect on the results in a postal questionnaire study? Eur J Epidemio/ 2001;17:80917. http://dx.doi.org/10.1023/A:1015615130459

18. Laatikainen T, von Hertzen L, Koskinen J-P, et al. Allergy gap between Finnish and Russian Karelia on increase. Allergy 2011;66:886-92. http://dx.doi.org/ 10.1111/j.1398-9995.2010.02533.x

19. Piirilä $P$, Pietinalho $A$, Loponen $M$, et al. The quality of spirometric examinations in Finland; results from a national questionnaire survey. Clin Physiol Funct Imag 2002;22:233-9. http://dx.doi.org/10.1046/j.1475-097X.2002.00424.x

20. Pietinalho A, Piirilä $P$, Poussa $T$, Lindholm $T$, Siukola A, Sovijärvi A. Spirometriatutkimusten laatu Suomessa jo hyvä - valtakunnallisen kyselytutkimuksen tulokset. Suom Lääkäril 2010;65:3505-12.

21. Bjerg A, Ekerljung L, Middelveld R, et al. Increased prevalence of symptoms of rhinitis but not of asthma between 1990 and 2008 in Swedish adults: comparisons of the ECRHS and GA2LEN surveys. PLOS ONE 2011;6(2):e16082. http://dx.doi.org/10.1371/journal.pone.0016082

22. Anandan C, Nurmatov $U$, van Schayck OCP, Sheikh A. Is the prevalence of asthma declining? Systematic review of epidemiological studies. Allergy 2010;65:152-67. http://dx.doi.org/10.1111/j.1398-9995.2009.02244.x

23. Eriksson J, Ekerljung L, Lötvall J, et al. Growing up on a farm leads to lifelong protection against allergic rhinitis. Allergy 2010;65:1397-403. http://dx.doi.org/10.1111/j.1398-9995.2010.02397.x

24. Pietinalho A, Kinnula V, Sovijärvi A, et al. Chronic bronchitis and chronic obstructive pulmonary disease. The Finnish Action Programme, interim report. Respir Med 2007;101:1419-25. http://dx.doi.org/10.1016/j.rmed.2007.01.022

25. Kinnula VL, Vasankari T, Kontula E, Sovijarvi A, Saynajakangas O, Pietinalho A. The 10-year COPD Programme in Finland: effects on quality of diagnosis, smoking, prevalence, hospital admissions and mortality. Prim Care Respir J 2011;20:178-83. http://dx.doi.org/10.4104/pcrj.2011.00024

26. Murray CJ, Lopez AD. Alternative projections of mortality and disability by cause 1990-2020: Global Burden of Disease Study. Lancet 1997;349:1498-504. http://dx.doi.org/10.1016/S0140-6736(96)07492-2

27. Halbert RJ, Isonaka S, George D, Iqbal A. Interpreting COPD prevalence estimates. What is the true burden of disease? Chest 2003;123:1684-92. http://dx.doi.org/10.1378/chest.123.5.1684

28. Pena VS, Miravitlles M, Garbiel R, et al. Geographic variations in prevalence and underdiagnosis of COPD. Results of the IBERPOC multicentre epidemiological study. Chest 2000;118:981-9. http://dx.doi.org/10.1378/chest.118.4.981

29. Lundbäck $B$, Lindberg $A$, Lindström $M$, et al. Not 15 but $50 \%$ of smokers develop COPD? - Report from the Obstructive Lung Disease in Northern Sweden Studies. Respir Med 2003;97:115-22. http://dx.doi.org/10.1053/rmed.2003.1446

30. Kotaniemi J-T, Sovijärvi A, Lundbäck B. Chronic obstructive pulmonary disease in Finland: prevalence and risk factors. COPD 2005;3:331-9. http://dx.doi.org/10.1080/15412550500218122

31. Vasankari TM, Impivaara O, Heliövaara M, et al. No increase in the prevalence of COPD in two decades. Eur Respir J 2010;36:766-73. http://dx.doi.org/ 10.1183/09031936.00178109

\section{Available online at http://www.thepcrj.org}

